\title{
Nekateri geografski vidiki rodnostnega obnašanja na izbranih primerih (v Sloveniji)
}

\section{Damir Josipovič}

Mag., Geografski inštitut Antona Melika, Znanstvenoraziskovalni center SAZU, Gosposka 13, 1000 Ljubljana, Slovenija

e-mail: damir.josipovic@zrc-sazu.si

\section{Izvleček}

Članek prikazuje primer aplikacije geografije pri proučevanju rodnostnega obnašanja. S pomočjo analize uradnih statističnih podatkov in analize $z$ anketo zbranih podatkov smo primerjali tri območja v Sloveniji (Prekmurje, Zasavje, območje upravne enote Domžale), in sicer na področju urbanosti, reliefa in etničnosti. Ugotovitve kažejo na določene primerjalne prednosti in potencial geografskega pristopa k študiju rodnosti.

Ključne besede: rodnostno obnašanje, dejavniki rodnosti, demogeografija, demografija, Slovenija

\section{Some Geographical Aspects of Fertility Behaviour in Selected Examples (in Slovenia)}

\begin{abstract}
The article presents the case of an application of geography in fertility behaviour studies. Analyzing the official statistical data and the data collected by an inquiry, we compared three areas in Slovenia (Prekmurje, Zasavje, administrative unit of Domžale) in a field of urbanity, relief and ethnicity. The findings point to certain comparative advantages and potential of geographical approach to fertility studies.
\end{abstract}

Key words: fertility behaviour, factors of fertility, demogeography, demography, Slovenia 


\section{UVOD}

Rodnost je tista sestavina prebivalstva, ki omogoča njegov obstoj. Narava človekove reprodukcije se je skozi zgodovino precej spreminjala. Verjetno najsilovitejše spremembe je doživela $\mathrm{v}$ zadnjih treh stoletjih nekako vzporedno $\mathrm{s}$ spremembami v načinu in oblikah ekonomske produkcije (Caldwell, 1979; Becker, 1981; Kaa, 1987; Oppenheim Mason, 1997). Te spremembe so bile tako korenite, da v večini gospodarsko razvitejših držav danes več ne moremo govoriti o spontanosti človekove reprodukcije. Rodnost je postala vse bolj načrtovana in zavestno omejevana. Slednja dva procesa sta pripeljala $v$ osredje posameznika, ki v skladu $\mathrm{z}$ okoliščinami, $\mathrm{v}$ katerih živi, usmerja in aktivno vpliva na svojo rodnost. Tako postaja rodnostno obnašanje prebivalstva tisti 'objekt' proučevanja, čigar razumevanje pomeni tudi razumevanje človekove reprodukcije kot take (Josipovič, 2002).

V Sloveniji se zadnji dve desetletji srečujemo z upadanjem števila rojstev pod raven, ki še omogoča enostavno reprodukcijo prebivalstva. Ker je pri nas rodnost že dolgo načrtovana so se tudi osebne želje in predstave o idealnem številu otrok spremenile. Idealno oziroma zaželeno število otrok se je precej zmanjšalo, realizacija teh želja pa se je zmanjšala še bolj. To je privedlo do zmanjševanja rodnosti pod samo-obnovitveni nivo, kar je že načelo temelje normalnega prebivalstvenega razvoja ne le $\mathrm{v}$ Sloveniji pač pa tudi $\mathrm{v}$ večini gospodarsko razvitejših držav. Za prikaz razvoja rodnosti sta uporabljena kazalnika končnega potomstva in celotne rodnosti (Graf 1). Prvi prikazuje povprečno število otrok na žensko po zaključenem fertilnem obdobju, drugi pa povprečno letno vrednost na podlagi vsakokratne porazdelitve rojstev po starosti mater.

Generacijska končna rodnost je padla pod samoobnovitveni nivo že v 50 . letih prejšnjega stoletja. Generacije, katerih rodnost ni zadoščala za enostavno reprodukcijo, pa so se rodile že v drugi polovici 20. letih 20. stoletja (Šircelj, 1998). Na drugi strani nas celotna rodnost kot transverzalni kazalnik na upad rodnosti pod nivo enostavne reprodukcije opozori šele v začetku 80. let.

Takšno je stanje na ravni celotne države. Ker pa pričakujemo, da tudi na področju rodnostnega obnašanja oziroma realizacije rodnosti prihaja do regionalnih razlik spodbujevanih s strani različnih dejavnikov, smo se odločili izbrati nekaj primerov območij z različno družbeno-geografsko strukturo. Za primer območja $s$ tradicionalno nadpovprečno zastopanostjo primarnega gospodarskega sektorja smo izbrali Prekmurje. Zasavje je bilo izbrano kot primer območja z dolgo rudarsko-industrijsko tradicijo. Kot primer območja z izrazitejšo zastopanostjo terciarnega gospodarskega sektorja pa je bilo izbrano območje upravne enote Domžale. 
Graf 1: Rodnost v Sloveniji v obdobju 1940-2001

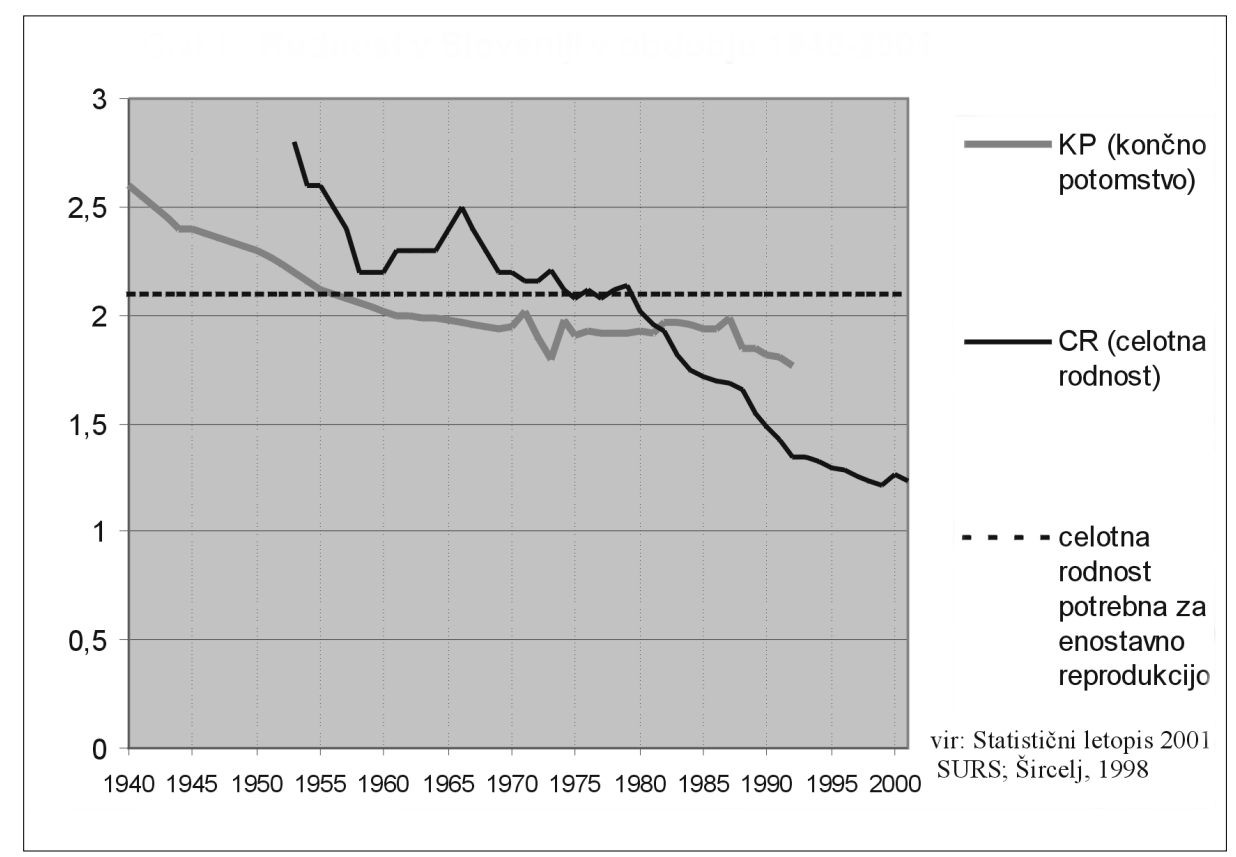

Karti 1 in 2 prikazujeta prostorsko razporeditev rodnosti triletnega povprečja 1998-2000 na nivoju občin v izbranih območjih. Za ta prikaz smo uporabili kazalnik aproksimativne celotne rodnosti (Josipovič, 2002, s. 35-37), ki pomeni celotno rodnost ocenjeno na podlagi letnega števila živorojenih in povprečne številčne zastopanosti enoletne fertilne ženske starostne skupine glede na srednjo letno velikost fertilne populacije. V našem primeru gre za triletna povprečja, s pomočjo katerih želimo nekoliko ublažiti letna nihanja.

Občine z najnižjimi vrednostmi rodnosti so pretežno na Dolinskem oziroma na ravnini. Obsegajo vsa urbana območja in prevladujejo znotraj dvojezičnega območja (Karta 1). Kljub temu, da je občina z najvišjo rodnostjo (Odranci) na ravninskem delu, občine na Goričkem izkazujejo višje vrednosti. Z najvišjimi vrednostmi prednjačita občini Moravče in Lukovica, ki se kot otok nahajata med dvema večjima urbanima conama - domžalsko in zasavsko. Tudi na teh dveh območjih so relativno nižje vrednosti $v$ bolj urbaniziranih občinah (Karta 2). Kljub temu, da znotraj in med območji razlike v rodnosti obstajajo, pa nobena občina v povprečju triletja 1998-2000 ni imela zadostne rodnosti niti za enostavno reprodukcijo. 
Karta 1: Ocena celotne rodnosti za obdobje 1998-2000 po občinah Prekmurja

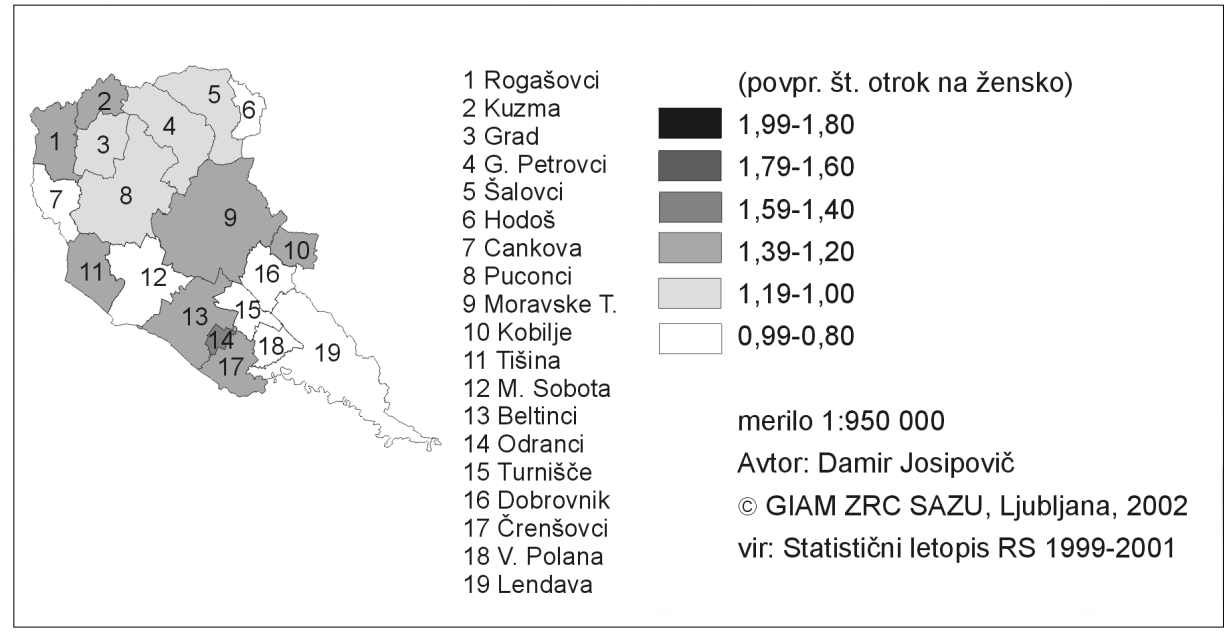

Karta 2: Ocena celotne rodnosti za obdobje 1998-2000 po občinah Zasavja in UE Domžale

\begin{tabular}{|c|c|}
\hline 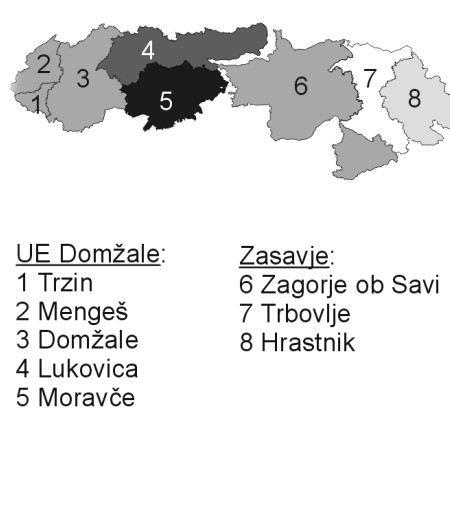 & $\begin{array}{l}\text { (povpr. št. otrok na žensko) } \\
1,99-1,80 \\
1,79-1,60 \\
1,59-1,40 \\
1,39-1,20 \\
1,19-1,00 \\
0,99-0,80 \\
\text { merilo 1:950 000 } \\
\text { Avtor: Damir Josipovič } \\
\text { C GIAM ZRC SAZU, Ljubljana, } 2002 \\
\text { vir: Statistični letopis RS 1999-2001 }\end{array}$ \\
\hline
\end{tabular}

Vzroke, ki vplivajo na raven rodnosti oziroma dejavnike rodnosti lahko razdelimo na več skupin. Ker je danes rodnost bolj kot od neposrednih vzrokov odvisna od posrednih dejavnikov rodnosti, bomo opredelili zgolj skupino slednjih. Najbolj podrobno klasifikacijo posrednih dejavnikov rodnosti je izdelal Malačič, ki jih je razdelil na šest skupin: biološki, ekonomski, družbeni, kulturni, antropološki in psihološki dejavniki (Malačič, 1985, s. 99; 2000, s. 115). 
Nekateri geografski vidiki rodnostnega obnašanja na izbranih primerih (v Sloveniji)

Po našem mnenju imajo pomembno mesto med njimi tudi geografski dejavniki (Josipovič, 2002, s. 107-111), zato smo jih vključili v našo klasifikacijo. Teoretično bi lahko razdelili geografske dejavnike rodnostnega obnašanja na dve skupini: na tiste, ki izhajajo neposredno (primarno) iz geografskega okolja in so njegov sestavni del, ter na tiste, ki so geografsko diferencirani odraz nekega pojava, ki je kot predmet proučevanja $\mathrm{v}$ osnovni domeni druge znanosti. Tako ima vsak posredni dejavnik rodnosti svojo prostorsko ali pokrajinsko komponento, ki kaže njegovo diferencialno moč oziroma prostorsko ali pokrajinsko diferenciacijo.

\section{PRIMERJAVA UČINKOV RODNOSTNEGA OBNAŠANJA MED POSAMEZNIMI PROSTORSKIMI ENOTAMI NA PODLAGI URADNIH STATISTIČNIH PODATKOV}

Možnosti geografije oziroma njen doprinos k razlagi rodnostnega obnašanja smo prikazali na podlagi primerjave učinkovanja treh dejavnikov v naših izbranih območjih in sicer z upoštevanjem geografskega vidika urbanosti, reliefa in etničnosti. S pomočjo analize uradnih statističnih podatkov in analize $\mathrm{z}$ anketo zbranih podatkov smo prišli do nekaterih ugotovitev, ki kažejo na določene primerjalne prednosti in potencial geografskega pristopa $\mathrm{k}$ študiju rodnosti.

\subsection{Urbanost}

Izbrana območja smo na osnovi Vrišerjeve (1995) opredelitve mestnih naselij razdelili na urbana in ruralna ter jih primerjali z vidika rodnosti. Cilj te primerjave je, da preverimo v teoriji zastopano stališče, da se urbano prebivalstvo, ali prebivalstvo urbanih sredin, drugače rodnostno obnaša od prebivalstva ruralnih območij. Razlika je v tem, da so mesta kot motor splošnega družbenega razvoja hkrati zelo restriktivna na področju rodnosti (Kaa, 1987; Boh, 1988; Černič Istenič, 1994; Šircelj, 1998). Večjo rodnostno ekspanzijo je torej pričakovati v ruralnih sredinah. Kljub splošnemu padcu ravni rodnosti v luči druge demografske tranzicije in manjšanju razlik med mesti in podeželjem, velja ta teza na vseh izbranih območjih (Preglednica 1). Razlike niso zanemarljive. Največje so v Zasavju, kjer je rodnost ruralnega območja za več kot dve petini višja kot v urbanem območju. Tam je ločnica med urbanim in ruralnim najostrejša (Nacionalni atlas Slovenije, 2001, s. 98). V drugih dveh območjih so razlike manjše, a je rodnost $v$ ruralnih območjih še vedno za petino višja kot $v$ 
urbanih območjih. Ob tem je treba upoštevati, da suburbanizacija, ki poteka v okolici urbanih naselij, prinaša tudi deagrarizacijo, z njo pa se spreminja »povprečno« obnašanje prebivalstva (Pelc, 1993, s. 86-87). Te spremembe se kažejo tudi v rodnostnem obnašanju. Zato je pričakovati, da so na območjih prostorsko obsežnejše suburbanizacije (npr. UE Domžale) ravno zaradi vpliva »mestnega obnašanja« razlike manjše tudi na področju rodnosti.

Preglednica 1: Aproksimativna celotna rodnost v obdobju 1998-2000 za posamezna območja glede na urbani ali ruralni značaj naselij

\begin{tabular}{|l|c|c|c|c|}
\hline območje & $\begin{array}{c}\text { urbano } \\
\text { območje }\end{array}$ & $\begin{array}{c}\text { ruralno } \\
\text { območje }\end{array}$ & $\begin{array}{c}\text { absolutna } \\
\text { razlika }\end{array}$ & $\begin{array}{c}\text { relativna } \\
\text { razlika }\end{array}$ \\
\hline PREKMURJE & 0,94 & 1,13 & $+0,19$ & $+20,2 \%$ \\
\hline ZASAVJE & 0,99 & 1,41 & $+0,42$ & $+42,4 \%$ \\
\hline UE DOMŽALE & 1,28 & 1,50 & $+0,22$ & $+17,2 \%$ \\
\hline
\end{tabular}

(vir: SURS, statistična raziskovanja Prijava rojstva (DEM-1), Prijava smrti (DEM-2), Naravno gibanje. Uporaba in objava podatkov, v celoti ali deloma, dovoljena z navedbo vira)

\subsection{Relief}

Drugi izbrani geografski vidik rodnostnega obnašanja je relief. Izbrana območja smo notranje razdelili na ravninsko-dolinski (nižinski) tip reliefa in na gričevnato-hriboviti (višinski) tip reliefa. Pri razvrstitvi smo se naslonili na že obstoječe klasifikacije (Pelc, 1993, s. 51-57; Kert, 1991), na opise naselij v Priročnem krajevnem leksikonu Slovenije (1996) in na lastno terensko opazovanje (Josipovič, 1998). Ta razdelitev je relativna. V Prekmurju je razlika med nižinskim (Ravensko in Dolinsko) in višinskim (Goričko) bistveno manjša kot denimo v Zasavju. Vendar znotraj območij obstaja dokaj jasna diferenciacija med tema dvema reliefnima tipoma. Rodnost prebivalstva $v$ višinskem območju je bila v vseh treh območjih višja kot v nižinskem območju (Preglednica 2). Velikost razlik je verjetno odvisna tudi od reliefne energije, ki je v Zasavju najvišja, v Prekmurju pa najnižja. To pa nima nobene zveze s precej razširjenim laičnim mnenjem, da je za hribovite predele značilna nizka rodnost (Barbič, 1993). Na podlagi ugotovljenih razlik, lahko vsaj z vidika naših izbranih območij to mnenje zavrnemo.

Poleg ugotovljenih razlik v rodnosti med posameznimi reliefnimi enotami nas je zanimala tudi statistična povezanost med rodnostjo in reliefom. $\mathrm{S}$ pomočjo uporabe hi-kvadrat preizkusa smo ugotovili, da sta nivo rodnosti $\mathrm{v}$ danem naselju in reliefna enota, kjer se dano naselje nahaja, medsebojno odvisna. Znotraj izbranih območij je rodnost višja v »višjem《 območju (Josipovič, 2002, s. 166-7). 
Nekateri geografski vidiki rodnostnega obnašanja na izbranih primerih (v Sloveniji)

Preglednica 2: Aproksimativna celotna rodnost v obdobju 1998-2000 za posamezna območja glede na relief

\begin{tabular}{|l|c|c|c|c|}
\hline območje & $\begin{array}{c}\text { ravninsko- } \\
\text { dolinsko }\end{array}$ & $\begin{array}{c}\text { gričevnato- } \\
\text { hribovito }\end{array}$ & $\begin{array}{c}\text { absolutna } \\
\text { razlika }\end{array}$ & $\begin{array}{c}\text { relativna } \\
\text { razlika }\end{array}$ \\
\hline PREKMURJE & 1,05 & 1,22 & $+0,17$ & $+16,2 \%$ \\
\hline ZASAVJE & 1,01 & 1,44 & $+0,43$ & $+42,6 \%$ \\
\hline UE DOMŽALE & 1,33 & 1,78 & $+0,45$ & $+33,8 \%$ \\
\hline
\end{tabular}

(vir: SURS, statistična raziskovanja Prijava rojstva (DEM-1), Prijava smrti (DEM-2), Naravno gibanje. Uporaba in objava podatkov, v celoti ali deloma, dovoljena $z$ navedbo vira)

Seveda reliefa kot geografskega faktorja rodnostnega obnašanja ne gre jemati izolirano od ostalih, temveč dialektično kot vse ostale. To pomeni, da moramo biti $\mathrm{v}$ kontekstu proučevanja rodnostnega obnašanja pozorni na vse spremembe v pokrajini, ki so lahko posledica različnega reliefa (Požeš, 1993). Tu imamo $\mathrm{v}$ mislih predvsem vlogo reliefa $\mathrm{v}$ morfologiji in fizionomiji naselij, $\mathrm{v}$ razvoju prometnega omrežja in infrastrukturne opremljenosti ter s tem povezane perifernosti tako $v$ smislu fizične dostopnosti kot $v$ smislu difuzije informacij oziroma vztrajanja tradicionalnih struktur v povezavi s splošnim razvojem rodnosti. Industrializacija, urbanizacija, modernizacija in drugi z njimi povezani procesi so temeljni element sodobnih teorij prebivalstva, ki $\mathrm{v}$ njih vidijo glavne prožilce sprememb v rodnostnem obnašanju prebivalstva (Oppenheim Mason, 1997; Natek, 1993). Ti procesi pa so se širili ravno iz žarišč, katerih lokacija je bila poleg razmer splošne zmožnosti preživetja $v$ največji meri odvisna od reliefa. Iz tega lahko izpeljemo, da ima v determinaciji rodnosti relief vlogo sintetičnega dejavnika, ki v sebi združuje vrsto parcialnih dejavnikov.

\subsection{Etničnost}

$\mathrm{Na}$ vzorčnih območjih kot etnična skupina prevladujejo Slovenci. V Prekmurju predstavljajo 86,2 \%, v Zasavju 87,3, v UE Domžale 92,0 \%, skupno v Sloveniji pa 87,8 \% (vir: Popis prebivalstva 1991, SURS). Deleži nam kažejo, da so bila razmerja po izbranih območjih dokaj podobna in blizu državnega povprečja. Kljub temu so po območjih obstajale precejšnje notranje razlike. Variabilnost deležev se je kazala tudi v odvisnosti od prostora. Mestna območja so tradicionalno privlačila najrazličnejše prebivalstvo in tako so bila tudi $\mathrm{v}$ pogledu etnične strukture bolj pestra od ruralnega zaledja.

Za opredelitev vloge etnične pripadnosti v rodnostnem obnašanju smo si pomagali s popisnimi podatki iz leta 1991, ker podatkov popisa 2002 še ni na 
voljo, ter jih primerjali z oceno celotne rodnosti v triletju 1998-2000. Verjetno se etnična struktura $\mathrm{v}$ zadnjem desetletju ni kaj dosti spremenila, saj se je priseljevanje zelo zmanjšalo. To pa na nek način upravičuje uporabo časovno različnih podatkov. Pearsonov koeficient korelacije se je ob $\mathrm{P}<0,01$ gibal med 0,320 v UE Domžale in 0,174 v Zasavju ter 0,159 v Prekmurju. To pomeni, da obstaja v vseh treh območjih nizka do zmerna (po Sagadin, 1992, s. 152-154) pozitivna povezanost med deležem Slovencev in rodnostjo. To potrjuje ugotovitve V. Šircelj (1991). Po drugi strani pa ne smemo zanemariti dejstva, da se je delež Slovencev tekom povojnega priseljevanja najbolj znižal v urbanih sredinah. Tudi ta podatek je treba upoštevati pri presoji rodnostnega obnašanja. Vemo namreč, da so urbana okolja načeloma bolj »prijazna« do družin z manj otroki. To po drugi strani pomeni, da se priseljenci prilagodijo novim razmeram (če so bile te drugačne kot na izvornih območjih!) in se obnašajo enako ali podobno celotni urbani populaciji. Zato je potrebna previdnost pri trditvah, ali je vzrok za nižjo rodnost različna etnična pripadnost, urbani značaj, ali kaj tretjega.

V Prekmurju smo ugotavljali tudi povezavo med rodnostjo avtohtonih etničnih manjšin in etnično večinskega prebivalstva. Rezultati za madžarsko skupnost so podobni skupini tistih, ki se niso opredelili kot Slovenci ( $\mathrm{r}=-$ $0,160 ; \mathrm{P}<0,001)$. To je razumljivo, saj največji delež med njimi predstavljajo ravno Madžari. Zanje je značilna geografsko zaključena in pretežno sklenjena ruralna poselitev, ki ni nastala kot posledica imigracije, temveč predvsem kot posledica madžarizacije ogrskih Slovencev (Zelko, 1996, s. 243). Zanimiva pa je razlika v nivoju rodnosti med Goričanskimi $(1,38)$ in Dolinskimi $(0,87)$ Madžari. Ker je dvojezično območje na Goričkem številčno šibko, je logičen majhen vpliv na vrednost ocene celotne rodnosti na celotnem dvojezičnem območju, ki znaša le 0,91 . V preostanku Prekmurja je omenjena vrednost 1,11 (Preglednica 3).

Preglednica 3: Aproksimativna celotna rodnost v obdobju 1998-2000 za posamezna območja glede na dvojezično območje v Prekmurju

\begin{tabular}{|l|c|c|c|c|}
\hline PREKMURJE & $\begin{array}{c}\text { dvojezično } \\
\text { območje }\end{array}$ & $\begin{array}{c}\text { preostanek } \\
\text { Prekmurja }\end{array}$ & $\begin{array}{c}\text { absolutna } \\
\text { razlika }\end{array}$ & $\begin{array}{c}\text { relativna } \\
\text { razlika }\end{array}$ \\
\hline SKUPAJ & $0,91^{*}$ & 1,11 & $+0,20$ & $+22,0 \%$ \\
\hline
\end{tabular}

(vir: SURS, statistična raziskovanja Prijava rojstva (DEM-1), Prijava smrti (DEM-2), Naravno gibanje. Uporaba in objava podatkov, v celoti ali deloma, dovoljena z navedbo vira) *Dolinsko: 0,87; Goričko: 1,38

Romi so naseljeni večinoma $\mathrm{v}$ zaselkih ali ločenih večjih naseljih, ki razen Püšče nimajo statusa samostojnega naselja. Osnovna os precej razpršene romske 
poselitve v Prekmurju poteka vzdolž reliktne translajtanske meje (Zupančič, Repolusk in Josipovič, 2000). Zaradi relativno nizkih deležev po naseljih, ki so posledica podcenjenosti števila Romov ob popisih, ne moremo reči, da je prisotnost Romov v nekem naselju izključen razlog za višjo rodnost naselja kot celote. Lahko pa rečemo, da prisotnost Romov rahlo pozitivno prispeva $\mathrm{k}$ višji skupni rodnosti naselja $(\mathrm{r}=0,083 ; \mathrm{P}<0,001)$. Po drugi strani rodnost Romov upada, njihovo rodnostno obnašanje pa je čedalje bolj podobno rodnostnemu obnašanju okoliškega prebivalstva (Zupančič, Repolusk in Josipovič, 2000, s. 21).

\section{PRIMERJAVA UČINKOV RODNOSTNEGA OBNAŠANJA MED POSAMEZNIMI PROSTORSKIMI ENOTAMI NA PODLAGI ANKETNIH PODATKOV}

Rezultate analize uradnih statističnih podatkov smo primerjali s podatki pridobljenimi z anketo leta 2001. Temeljni namen anketiranja je bil v prvi vrsti medsebojno primerjati izbrana območja pod enakimi pogoji. V našem primeru so osnovno populacijo pomenili starši prvošolčkov v šolskem letu 2000/2001 oziroma generacije otrok 1993/1994. Namesto iz vzorca žensk določene starosti, smo izhajali iz generacije učencev, ki so rezultat določenega rodnostnega obnašanja. V anketi smo se zavestno odrekli proučevanja fertilne populacije brez otrok. Velikost le-te lahko ocenimo s primerjavo velikosti populacije staršev in velikosti prebivalstva enake starosti nasploh, ali pa na podlagi v literaturi omenjenih deležev. Deleži izpolnjenih vprašalnikov so se približno gibali med $50 \%$ (UE Domžale) in 80 \% (Prekmurje), kar pomeni visok delež osnovne populacije (Josipovič, 2002, s. 50-1).

Območja so prikazana glede na anketno povprečno število otrok v družini (Preglednica 4, 5, 6). Pri Prekmurju smo vključili tudi dvojezično območje. Podatki kažejo, da je rodnost $\mathrm{v}$ dvojezičnem območju nižja kot $\mathrm{v}$ preostanku Prekmurja. Podatki za ugotavljanje nivoja rodnosti znotraj dvojezičnega območja pa so premalo številčni za kakršenkoli utemeljen sklep.

V nasprotju s statističnimi podatki, kaže anketa sicer majhne razlike $\mathrm{v}$ rodnosti glede na relief v prid nižinskemu območju znotraj Prekmurja. Na ostalih dveh območjih so anketni podatki potrdili razlike ugotovljene na podlagi statističnih podatkov. To pomeni, da je nivo rodnosti višji, če je relief višji in razgibanejši. Razloge za različen rezultat v Prekmurju gre iskati tudi v podpovprečni zastopanosti prebivalcev iz dvojezičnega območja na Goričkem. V anketi so predstavljali šestodstotni delež, po popisu 1991 pa so predstavljali približno petino vseh. 
Preglednica 4: Povp. število otrok glede na območje bivanja družin v Prekmurju

\begin{tabular}{|l|c|c|c|}
\hline OBMOČJE & N & Povpr. št. otrok & Delež \\
\hline mestna naselja & 143 & 1,91 & $21,2 \%$ \\
\hline ostala naselja & 530 & 2,03 & $78,8 \%$ \\
\hline madžarsko dvojezično območje & 90 & 1,84 & $13,1 \%$ \\
\hline preostanek Prekmurja & 597 & 2,02 & $86,9 \%$ \\
\hline nižinsko območje & 589 & 2,01 & $85,7 \%$ \\
\hline višinsko območje & 98 & 1,93 & $14,3 \%$ \\
\hline mestno središč & 65 & 2,08 & $9,6 \%$ \\
\hline mestno obrobje & 61 & 1,83 & $9,1 \%$ \\
\hline vaško središče & 352 & 2,03 & $52,2 \%$ \\
\hline vaško obrobje & 176 & 1,95 & $26,1 \%$ \\
\hline hiša na samem & 18 & 2,17 & $2,7 \%$ \\
\hline ločeno romsko naselje & 2 & 2,50 & $0,3 \%$ \\
\hline
\end{tabular}

(vir: Anketa 06/2001)

Preglednica 5: Povp. število otrok glede na območje bivanja družin v Zasavju

\begin{tabular}{|l|c|c|c|}
\hline OBMOČJE & N & Povpr. št. otrok & Delež \\
\hline mestna naselja & 207 & 1,90 & $84,5 \%$ \\
\hline ostala naselja & 38 & 2,18 & $15,5 \%$ \\
\hline nižinsko območje & 208 & 1,90 & $86,3 \%$ \\
\hline višinsko območje & 33 & 2,21 & $13,7 \%$ \\
\hline mestno središče & 90 & 1,77 & $36,9 \%$ \\
\hline mestno obrobje & 94 & 1,96 & $38,5 \%$ \\
\hline vaško središče & 26 & 2,27 & $10,7 \%$ \\
\hline vaško obrobje & 24 & 2,08 & $9,8 \%$ \\
\hline hiša na samem & 10 & 2,40 & $4,1 \%$ \\
\hline
\end{tabular}

(vir: Anketa 06/2001)

Preglednica 6: Povprečno število otrok glede na območje bivanja družin v UE Domžale

\begin{tabular}{|l|c|c|c|}
\hline OBMOČJE & N & Povpr. št. otrok & Delež \\
\hline mestna naselja & 108 & 2,12 & $45,4 \%$ \\
\hline ostala naselja & 130 & 2,33 & $54,6 \%$ \\
\hline nižinsko območje & 195 & 2,15 & $82,6 \%$ \\
\hline višinsko območje & 41 & 2,61 & $17,4 \%$ \\
\hline mestno središče & 26 & 2,08 & $11,0 \%$ \\
\hline mestno obrobje & 86 & 2,16 & $36,3 \%$ \\
\hline vaško središče & 77 & 2,30 & $32,5 \%$ \\
\hline vaško obrobje & 41 & 2,34 & $17,3 \%$ \\
\hline hiša na samem & 7 & 2,57 & $3,0 \%$ \\
\hline
\end{tabular}

(vir: Anketa 06/2001) 
Kar zadeva prebivalstvo mestnih in nemestnih naselij ter razlike med njimi, lahko rečemo, da je anketa na vseh treh območjih potrdila ugotovljene razlike. To pomeni, da je nivo rodnosti v mestnih območjih nižji. Ker smo menili, da je nivo rodnosti različen glede na tip naselja, smo stanovanja (prebivališča) anketiranih razdelili na različne skupine znotraj nekega naselja. Razlikovali smo mestno središče, mestno obrobje, vaško središče, vaško obrobje in hiše na samem, dodali pa smo še romsko naselje. Tudi tu vidimo, da prihaja do naraščanja navzven od mestnih središč. Ta gradient je najlepše viden na območju UE Domžale, še vedno izrazit je v Zasavju, nekoliko manj razviden pa je v Prekmurju.

Glede etnične strukture anketiranih je treba povedati, da Slovenci na vseh treh območjih močno prevladujejo. Kljub majhnemu številu drugih je razvidnih tudi nekaj zanimivih detajlov. Anketirane smo po območjih razdelili na dve večji skupini: Slovence in ostale (Preglednica 7,8). Za primerjavo realizacije rodnosti smo jih dodatno razdelili na dve starostni skupini: na mlajše, in na starejše, od 35 let. Ta meja je bila izbrana zaradi strukture zbranih podatkov in pa zaradi tega, ker se približno $95 \%$ rojstev realizira do te starosti (KožuhNovak et al., 1998, s. 40). Povprečno število otrok pri ženskah onkraj te starosti pa je že precej dober približek končnemu potomstvu (Josipovič, 2002, s. 190).

Preglednica 7: Neslovenske etnične pripadnosti anketirank po starosti in št. otrok

\begin{tabular}{|l|c|c|c|c|c|c|}
\hline \multirow{2}{*}{ starost } & \multicolumn{2}{|c|}{ PREKMURJE } & \multicolumn{2}{c|}{ ZASAVJE } & \multicolumn{2}{c|}{ UE DOMŽALE } \\
\cline { 2 - 7 } & N & Povpr. št. otrok & N & Povpr. št. otrok & N & Povpr. št. otrok \\
\hline$<35$ let & 32 & 1,78 & 17 & 1,94 & 7 & 2,57 \\
\hline 35 in več & 22 & 2,18 & 10 & 2,30 & 3 & 1,00 \\
\hline skupaj & 54 & 1,94 & 27 & 2,07 & 10 & 2,10 \\
\hline
\end{tabular}

(vir: Anketa 06/2001)

Preglednica 8: Slovenska etnična pripadnost anketirank po starosti in št. otrok

\begin{tabular}{|l|c|c|c|c|c|c|}
\hline \multirow{2}{*}{ starost } & \multicolumn{2}{|c|}{ PREKMURJE } & \multicolumn{2}{c|}{ ZASAVJE } & \multicolumn{2}{c|}{ UE DOMŽALE } \\
\cline { 2 - 7 } & $\mathbf{N}$ & Povpr. št. otrok & $\mathbf{N}$ & Povpr. št. otrok & N & Povpr. št. otrok \\
\hline$<35$ let & 305 & 1,85 & 105 & 1,72 & 103 & 2,15 \\
\hline 35 in več & 184 & 2,27 & 73 & 2,18 & 92 & 2,40 \\
\hline skupaj & 489 & 2,01 & 178 & 1,91 & 195 & 2,27 \\
\hline
\end{tabular}

(vir: Anketa 06/2001)

Število otrok v družinah, kjer se anketirane matere nimajo za etnične Slovenke, ni prav nič večje od družin, v katerih se anketiranke opredeljujejo kot Slovenke (Preglednica 7, 8). Rodnost tudi bolj variira med območji kot znotraj 
območij. V takih razmerah lahko praktično izključimo etnično pripadnost kot pomemben dejavnik rodnostnega obnašanja. Obstajajo pa izjeme, ko gre za sklenjeno in homogeno poselitev npr. Madžarov v Prekmurju. Zanje smo že poprej pokazali, da se rodnostno obnašajo prostorsko različno od drugih. Tu igra glavno vlogo geografski dejavnik prostora, v katerem Madžari nastopajo homogeno in dajejo pečat svojemu okolju in s tem tudi rodnostnemu obnašanju v njem.

$\mathrm{Z}$ anketo smo preverjali tudi prisotnost stereotipa o večji rodnosti prebivalcev, ki se ne opredeljujejo kot Slovenci. Ta je še vedno precej prisoten $\mathrm{v}$ Zasavju (pri moških $58 \%$, pri ženskah $59 \%$ ), nekoliko manj izrazit je v UE Domžale (m: $47 \%$, ž: $46 \%$ ), relativno najšibkejši pa je v Prekmurju (m: $28 \%$, ž: $26 \%$ ). Prisotnost stereotipov med anketiranimi po eni strani kaže na neke vrste ogroženost, ki izhaja iz »zavedanja« prebivalstva, da rodnost Slovencev oziroma v Sloveniji upada in da Slovenci izumirajo. Po drugi strani pa lahko opazimo, da je prisotnost tega stereotipa manjša v Prekmurju, kar lahko povezujemo tudi z mnenjem anketiranih, da tamkaj prevladujoča "neslovenska« etnična skupnost (Madžari) številčno ne »ogroža« Slovencev. Vzroke za razlike med Zasavjem in UE Domžale morda lahko iščemo v različnih deležih Slovencev (ta delež je na območju Domžal nekoliko višji), morda pa tudi v različni izobrazbeni strukturi. Le-ta je ugodnejša na območju UE Domžale.

\section{ZAKLJUČEK}

Rodnostno obnašanje je zapleten pojav, ki ima tudi geografske vidike in svojo prostorsko razsežnost. Pomembno vlogo pri oblikovanju rodnostnega obnašanja imajo tudi geografski dejavniki. S pomočjo analize uradnih statističnih podatkov in analize $\mathrm{z}$ anketo zbranih podatkov smo prišli do nekaterih ugotovitev, ki kažejo na določene primerjalne prednosti in potencial celovitega, večplastnega geografskega pristopa $\mathrm{k}$ študiju rodnosti. Ta pristop lahko pomeni tudi obogatitev izkušenj drugih strok, hkrati pa predstavlja poti do novih izsledkov, ki so lahko v pomoč tudi celoviti prebivalstveni politiki, ki je Slovenija še nima.

Ko govorimo o dejavnikih rodnosti, je treba opozoriti na njihovo kompleksnost. Zato jih moramo razumeti izključno dialektično, torej v stalni interakciji in medsebojni prepletenosti. Tu ni enostavnih vzročno-posledičnih zvez. Množica različnih dejavnikov v odvisnosti od časa in prostora različno vpliva na raven rodnosti. $\mathrm{V}$ tem kontekstu moramo razumeti tudi izmerjene povezave. Vsaka z veliko gotovostjo potrjena povezava nam kaže, da je primerjani dejavnik verjetno eden od kamenčkov v mozaiku prepletenega vplivanja na rodnost. Ravno geografska in časovna diferenciacija pa nam kažeta, da se 
jakost posameznih dejavnikov spreminja, da nekje delujejo še drugi dejavniki, ki jih spet drugje sploh ni, ali pa je njihovo delovanje neznatno. Pomen geografskega pristopa $\mathrm{k}$ proučevanju rodnosti je ravno teritorializacija problema, s tem pa je olajšano ne le razumevanje problema temveč tudi iskanje vzročnosti danim razmeram.

\section{Viri in literatura:}

Barbič, A., 1993. Samoobnavljanje kmečkega sloja. Sodobno kmetijstvo, 5, 209-217.

Becker, G. S., 1981. Treatise on the family. Massachusetts, Harvard University Press.

Bogataj, J. et al., 2001. Nacionalni atlas Slovenije. Ljubljana, IG, GIAM ZRC SAZU.

Boh, K., 1988. Poskus sociološke analize nizke rodnosti. Družboslovne razprave, 6, 23-32.

Caldwell, J. C., 1979. Economic rationality of high fertility. Population Studies, 33, 395-413.

Černič Istenič, M., 1994. Sociološki vidiki nizke rodnosti v Sloveniji. V: Stropnik, N. (ur.), Kaj potrebujemo: družinsko ali prebivalstveno politiko? Zbornik referatov 10. in 11. maja 1994, Portorož, 89-105.

Josipovič, D., 1998. Regionalni oris občine Kobilje in njeno mesto v Prekmurju. Seminarska naloga. Ljubljana, Filozofska fakulteta.

Josipovič, D., 2002. Geografske značilnosti rodnosti v izbranih območjih Slovenije. Magistrsko delo. Ljubljana, Filozofska fakulteta.

Kaa, D. J. van de, 1987. Europe's second demographic transition. Population Bulletin, 42, 1.

Kert, B., 1991. Regionalizacija subpanonske severovzhodne Slovenije. Dela 8, 25-31.

Kožuh-Novak, M. et al., 1998. Rodnostno vedenje Slovencev. Ljubljana, ZRC SAZU.

Malačič, J., 1985. Sodobno obnavljanje prebivalstva in delovne sile. Ljubljana, DZS.

Malačič, J., 2000. Demografija - teorija, analiza, metode in modeli. Ljubljana, Ekonomska fakulteta.

Natek, M., 1993. Sestavine prebivalstvene rasti v savinjskih občinah celjske regije.V: Pelc, S. (ur.), Savinjska - možnosti regionalnega in prostorskega razvoja. 16. zborovanje slovenskih geografov, Celje, 232-244.

Oppenheim Mason, K., 1997. Explaining fertility transitions. Demography 34, $4,443-454$. 
Orožen Adamič, M., Perko, D., Kladnik, D., 1996. Priročni krajevni leksikon Slovenije. Ljubljana, DZS.

Požeš, M., 1993. Socialnogeografske značilnosti krajevnih skupnosti Savinjske. V: Pelc, S. (ur.), Savinjska - možnosti regionalnega in prostorskega razvoja. 16. zborovanje slovenskih geografov, Celje, 248-256.

Sagadin, J., 1992. Osnovne statistične metode za pedagoge. Ljubljana, Filozofska fakulteta.

Statistični letopis, različni letniki. Ljubljana, Statistični urad R Slovenije.

Statistična raziskovanja Prijava rojstva (DEM-1), Prijava smrti (DEM-2), Naravno gibanje. Uporaba in objava podatkov, v celoti ali deloma, dovoljena $z$ navedbo vira. Ljubljana, SURS.

Šircelj, M., 1991. Determinante rodnosti v Sloveniji. Doktorska disertacija, Filozofska fakulteta, Ljubljana.

Šircelj, M., 1998. Demografski razvoj Slovenije. IB revija, 1-3, 65-80; 4-5, 63-79.

Vrišer, I., 1995. Opredelitev mest in mestnih občin v republiki Sloveniji. Dela $11,77-112$.

Zelko, I. 1996. Zgodovina Prekmurja. Murska Sobota.

Zupančič, J., Repolusk, P., Josipovič, D., 2000. Problematika Romov v občini Turnišče. Elaborat. Ljubljana, Inštitut za geografijo.

\section{SOME GEOGRAPHICAL ASPECTS OF FERTILITY BEHAVIOUR IN SELECTED EXAMPLES (IN SLOVENIA)}

\section{Summary}

Fertility behaviour is a complex phenomenon with its own spatial dimension. The intention of this article is to highlight this dimension and to show that geographical factors play an important role in the shaping of fertility behaviour. The possible contribution of geography to the explanation of fertility behaviour is presented on the basis of comparing three regions in Slovenia (Prekmurje, Zasavje, and the wider area of Domžale) in the fields of urbanization, relief, and ethnicity. With the analysis of official statistical data and the analysis of data collected with a questionnaire, we reached several conclusions that indicate certain comparative advantages and the potential of a geographical approach to studying fertility.

Our calculations confirm the hypothesis that the fertility behaviour of urban populations differs from the fertility behaviour of rural populations. The comparison of fertility relative to the type of relief showed that fertility in "highland" areas is higher as a rule than fertility in "lowland" areas. This find- 
ing counters the fairly widespread but quite mistaken belief that it is typical for highland areas to have low fertility. Relief acts as an extremely complex element of fertility since in itself it combines a series of factors that influence the fertility behaviour of population. Ethnicity as a factor of fertility behaviour reveals greater heterogeneity between regions than within regions. This means that differences in fertility relative to the ethnicity of the interviewees depend much more on the region in which the fertility is realized. Owing to the considerable differences between regions and the smaller differences within regions, it can be said that ethnicity is not a particularly strong factor in fertility behaviour, except in the case of the Hungarians in Prekmurje where the area of settlement is geographically compact and clearly defined.

With the exception of Prekmurje, the results of the analysis of the questionnaire data match the results of the analysis of the official statistical data regarding higher fertility in highland regions. The questionnaire analysis also confirmed findings regarding the higher fertility in rural settlements in all three regions. Related to this is the finding that fertility increases with the distance from urban centers. This finding roughly applies to all three regions, although the gradient of increase is most clearly seen in the Domžale area. We can also confirm the fact that the bilingual area in Prekmurje has a lower fertility than the rest of Prekmurje. 